\title{
Sobre o estatuto do psiquismo no projeto hermenêutico de Wilhelm Dilthey
}

Prof. Dr. Roberto Saraiva Kahlmeyer-Mertens IFCH-UERJ

Bacharel em filosofia Eduardo H. Silveira Kisse IFCS-UFRJ

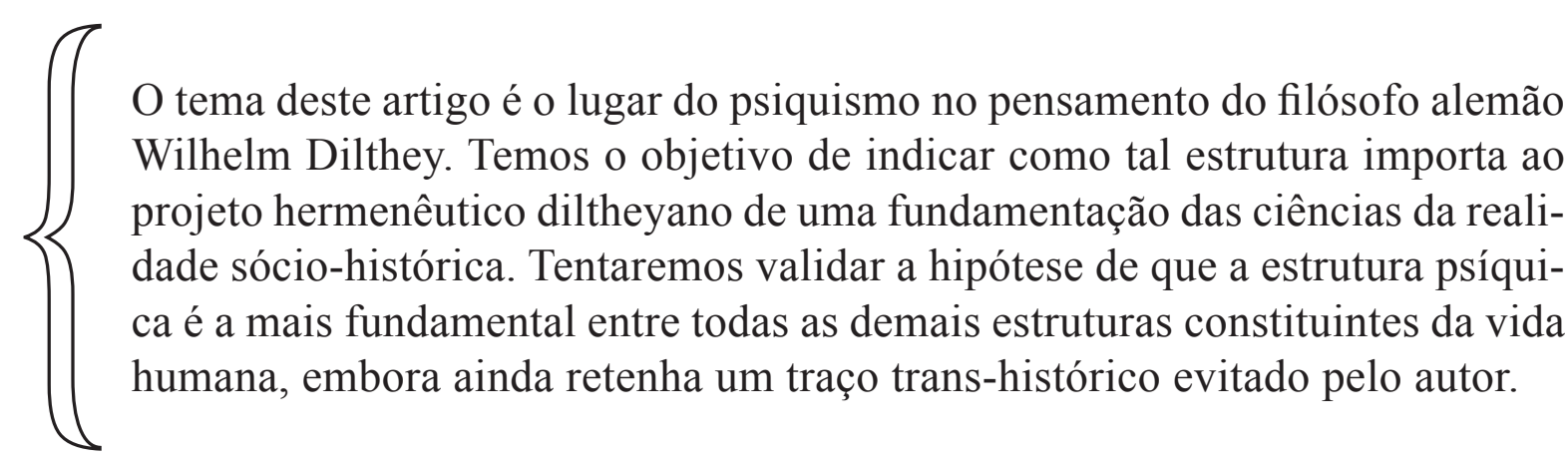

PALAVRAS-CHAVE

Hermenêutica, Dilthey, psiquismo, expressão da vivência, trans-historicidade

The theme of this essay is the place of the psychism in the thought of German philosopher Wilhelm Dilthey. The aim is to indicate how this structure is important to the project diltheyano a foundation of science socio-historical reality. We will try to validate the hypothesis that psychic structure is the most fundamental structures of all other constituents of human life, showing also that this is trans-historical. 


\section{Introdução}

O presente trabalho procura investigar o estatuto do psiquismo na filosofia de Wilhelm Dilthey (1833-1911). Com este, pretendemos saber qual o papel do psiquismo na filosofia do autor alemão. Temos o objetivo específico de apresentar, de maneira sucinta, os pressupostos que envolvem tal noção na filosofia diltheyana, especificamente na obra Teoria das concepções de mundo (1992). Além disso, indicaremos como Dilthey estabelece a estrutura psíquica como a mais fundamental epistemologicamente, já que o filósofo busca uma entidade não trans-histórica para combater o idealismo dos empiristas ingleses, bem como o idealismo transcendental kantiano. Julgamos poder sustentar que a resposta ao nosso problema revelará que, na filosofia de Dilthey, o psiquismo é a mais fundamental de todas as estruturas constituintes da vida.

\section{Do embate com o idealismo transcendental kantiano e com o empirismo inglês: o "pano de fundo" para a fundamentação das ciências históricas e da sociedade}

Na sua principal obra, a Introdução às ciências humanas, Dilthey desenvolve uma "crítica da razão histórica", fazendo clara alusão ao projeto crítico kantiano através da delimitação das condições de conhecimento frente à realidade histórica. Ao contrário de Kant, que fundamenta todo o conhecimento possível em formas a priori, Dilthey negará a concepção de um homem transcendental, abstrato e puro em seu pensar, para buscar embasar o conhecimento na experiência de modo não apriorístico. (LESSING, 2011).

E será, igualmente, na busca por fundamentos não idealistas, que Dilthey terá os empiristas ingleses como adversários, já que eles estabelecem a ideia de um homem idealizado como objeto de estudos de suas ciências morais. De acordo com Gadamer (1998), essas ciências obedeceriam às mesmas premissas orientadoras das ciências naturais.

Dilthey concordaria sem dificuldades com o fato de as ciências morais estarem necessariamente conectadas ao homem, mas seria muito crítico com a ideia de "natureza humana", pois esta só existiria na abstração de um homem sem qualquer contato com sua realidade vivida, vigorando apenas num plano idealista. E seria exatamente neste sentido que John St. Mills teria suas moral sciences 
traduzidas para o alemão por Geisteswissenschaften ("ciências do espírito" ao pé da letra). (MAKKREEL, 1984) O alemão Matthias Jung afirma, em seu Dilthey zur Einführung (1996), que o pensamento diltheyano diferencia a realidade humana da natural, enquanto mera abstração:

A tradução inglesa para o conceito "Geisteswissenschaften", "human sciences", expressa essa orientação nas conexões de sentido da realidade histórico-social melhor do que sua contraparte alemã, na qual "espírito" pode facilmente ser entedido como algo auto-suficiente, independente da lida de homens reais. (JUNG, 1996, p. 8)

A Teoria das concepções de mundo ${ }^{1}$ de Dilthey nos fornecerá material suficiente para investigar como o filósofo combaterá o idealismo transcendental proposto por Kant, bem como a natureza humana encontrada no empirismo, na medida em que pesquisarmos em que fundamento último se encontraria a concepção diltheyana de homem.

\section{A consciência histórica na interface do conceito diltheyano de psiquismo}

O desenvolvimento do presente artigo depende da exposição dos principais conceitos da referida obra. Deste modo, buscando dar ciência ao leitor do contexto em que nossa temática se move, introduziremos, sumariamente, alguns dos conceitos-chave abordados na introdução da obra de Dilthey.

No primeiro capítulo de Teoria das concepções de mundo, encontramos o filósofo nos apresentando a um problema proveniente de um tipo de consciência nascido em sua época: a consciência histórica. Tal conceito poderia ser definido como o privilégio do homem moderno de ter consciência da historicidade de todo presente e da relatividade de cada opinião. Com base nisso, ainda poderíamos ponderar o quanto seria contrassenso, doravante, deter-se na segurança ingênua de uma tradição histórica solipsista. Dado que só confirma a posição que sustenta a existência de uma entidade apriorística imutável, na forma de uma natureza humana. (GADAMER, 1998).

1 Apesar de ser um manuscrito e de não ter sido terminada por conta de sua morte, tal como sua obra principal e diversas outras, que também permaneceram inacabadas. 
A consciência histórica, tal como pensada aqui, contudo, conduziu o pensar de uma época a uma certa descrença, uma vez que (logo que percebida a relatividade dos saberes de cada período histórico e seus respectivos condicionantes) passou a ser propagada a ideia de que seria impossível sustentar qualquer verdade. Uma ideia de verdade, fosse ela qual fosse, estaria, assim, condicionada a valores historicamente estabelecidos e, por isso mesmo, não poderia mais ser considerada universal. O ceticismo, reputado por muitos uma "nódoa" na filosofia (RODI, 1985, p.147), tal como surgiu, fez Edmund Husserl acusar Wilhelm Dilthey de historicista. Historicismo, este, que significaria um relativismo desprovido de orientação.

A Dilthey, entretanto, não caberia a qualificação de historicista, pois sua lida com a história faria dele, quando muito, um "historista". Ou seja: um adepto da mesma doutrina de pensamento na qual Droysen, Ranke e Savigny eram distintos propositores. Historismo, portanto, seria um ensinamento que teria como principal característica a compreensão das transformações históricas de cada cultura, indo de encontro a qualquer reivindicação de razão absoluta e universal. Dilthey apresenta, assim, o problema do historicismo na forma da seguinte antinomia: historicamente, foram criados inúmeros sistemas metafísicos (além de sistemas religiosos e diferentes correntes artísticas...), estes que concorriam sempre na demonstrabilidade objetiva da realidade. Cada um desses sistemas seria, no entanto, condicionado pelo tipo de consciência vigente de sua época, como nos diz o filósofo: "ao ideal da vida e à mundividência está sempre subjacente uma complexão de ânimo e só para o âmbito histórico têm eles validade." (DILTHEY, 1992, p.19). Com qual legitimidade pode-se, então, erguer um sistema metafísico (um sistema que tente descrever objetivamente a realidade), se ele é dependente de questões subjetivas variantes?

Um caminho reconhecido pelo filósofo para responder a questão acima reside no fato de que cada um destes sistemas serem expressão da vivência de sua visão de mundo. As contradições nasceriam, portanto, da autonomização destas expressões na forma de sistemas metafísicos. Autonomização significa, aqui, a abstração da realidade vivida, criando-se sistemas hipotéticos para se tentar explicar a vida. Isso significa "desvificação", na medida em que se cria um mundo de entidades apartadas de toda e qualquer vivência. Dilthey (2012) sugere que se reveja a relação existente entre esta autonomização e a vivência, para que advirta que: 1. esta antinomia se funda na diversidade histórico-cultural daquilo que Dilthey indicará como uma estrutura inerente ao homem; 2. se esta autonomia surge como expressões de diferentes formas de vivência, não há contradição, mas apenas uma diversidade de sistemas; 3. a contradição entre arte, 
religião e metafísica consiste no fato de que apenas uma delas pode ter razão, sendo sistemas excludentes. Acaba-se com esta contradição ao entender-se que esses três sistemas são apenas modos de expressão próprios da vivência.

\section{Conceitos de base na "psicologia" das visões de mundo segundo Dilthey}

O que tratamos aqui por "expressão da vivência" consiste na maneira com a qual o homem torna objetivo o âmbito do sujeito por meio da visão de mundo. Isto, para Dilthey, se diferencia do modo com que Kant compreende a objetividade e a subjetividade. Para Kant, a relação sujeito-objeto é dada no conhecimento do objeto, através da relação lógica entre causa e efeito. (Cf. DILTHEY, 2011) Segundo Dilthey, a mundividência (longe de se dar por vias cognitivas ou lógico-causais) leva em conta a consciência histórica, apoiada numa subjetividade-histórica. Segundo Jung (1996), o elemento central da filosofia da vida de Dilthey está no fato de nossa interpretação da realidade não ser cognitiva desde o início. Esta, afinal, contaria com orientações fornecidas por valores, enredos e vontades, que não podem ser separados de uma cosmovisão específica. Tal avaliação poderia ser legitimada pelas ideias do próprio Dilthey, quando o autor afirma que toda "circunstância empírica manifesta-se como simpatia, sentimento de honra, consolidação da nossa vida afetiva como assentimento, em suma, de mil maneiras". (DILTHEY, 1992, p.32).

Podemos entender, mediante isso, que o filósofo considera a vida como fundamentalmente conectada a um mundo, como que numa estrutura reflexa, pois, do mundo, a vida recebe influências e, por causa delas, tende a manifestar-se. Essas manifestações também seriam tentativas de se expor, objetivamente, o que acontece na vida psíquica. (Cf. LESSING, 2011). A vida psíquica não deve ser entendida como apenas mais uma entre diversas outras vidas que, em conjunto, formariam o que chamamos de homem e que podem dar-se de forma completamente independente cada uma de outra, pois elas todas se influenciam mutuamente e em algum momento. O psiquismo é, sim, uma estrutura fundamental à formação da vivência, mas que se diferencia das outras estruturas pelo fato de ser aquela onde se manifesta a experiência de vida, sendo seus desdobramentos não somente a expressão da vivência, mas também consciência de si mesmo. (DILTHEY, 1992). A vida psíquica é base para a consciência de 
si, através da diferença e distanciamento da consciência do outro, assim como fenomenologia de Hegel. Desse modo, Dilthey faz referência à consciência e vida psíquica utilizando termos como interior e interioridade. Destarte, ainda segundo o Dilthey, é parte de nossa estrutura psíquica uma interioridade que busque expressão numa exterioridade. Deste modo, a expressão, deveria partir de uma auto-interpretação da vida (fundada na visão interior), e não teria seu fundamento primeiro no exterior (realidades isoladas), mas através de valorações e volições.

As referidas valorações, contudo, são como que adquiridas ou formadas ao longo da história. De acordo com Dilthey (1992), elas nem sempre existiriam, uma vez que elas são desenvolvimentos da vida psíquica que, em suas condições mais básicas, tem vida anímica. A vida anímica é a unidade que sustenta a diversidade das percepções psíquicas do mundo que formamos empiricamente, além de, por sua vez, ser resultante do sujeito no mundo, uma relação fundamental e correlacional. Com o termo fundamental, Dilthey faz referência ao fato desta relação ser a condição mais necessária e básica para todo posterior desenvolvimento da vida psíquica. Isso porque, sendo ela correlacional, o mundo e o sujeito seriam correlatos. E, como o mundo é objeto de um sujeito e um sujeito pressupõe sempre um objeto, o correlato está sempre para o sujeito como uma objetalidade. Vale, aqui, destacar que Dilthey fala de objetividade (Objektivität) e não de objetivismo (Objektivismus), sendo o primeiro um referencial à tensão entre o sujeito e o objeto de sua epistemologia, e o segundo sendo o modo como os positivistas em geral tratam das ciências do homem.

Os positivistas assumem a posição de que tudo pode ser compreendido segundo as ciências naturais, o que pode ser considerado um erro metodológico. Eles tentam aplicar as leis das ciências naturais (algumas dessas como o evolucionismo, o mecanicismo e a relação lógico-causal, por exemplo) ao mundo das ciências sócio-históricas. Contrariamente a isso, o que Dilthey argumenta é que o mundo, tal como observado, é uma objetalidade separada do mundo do sujeito (interior) não podendo este mundo interior ser explicado pelo outro (exterior).

Enquanto o objeto das ciências naturais é resultado da observação do mundo exterior, o objeto das ciências humanas é resultado da observação do mundo interior, sem abstrações ou mediações. Desta maneira, fica entendido que não seria pensável de modo algum encaixar nem o positivismo nem o objetivismo no projeto filosófico de Dilthey, pois ele os combate fortemente. (DILTHEY, 2010b). Sendo o sujeito e o mundo correlatos (como se indicou acima), en- 
tende-se que o ideal da vida e a visão de mundo (inclua-se nisto também as valorações e as volições) também o sejam. Elevando esta relação entre o ideal da vida e a visão de mundo à consciência de si, tem-se a vivência, que não é "relação do pensamento e outros estados espirituais" (DILTHEY, 1992, p.58), mas consciência da vida, consciência do que se é experimentado na totalidade da relação entre o si mesmo e o mundo.

Portanto, epistemologicamente, a estrutura da vida psíquica, em suas bases mais simples, é também a mais fundamental para todas as outras estruturas e, consequentemente, para a vivência, (se entendida como totalidade entre o si mesmo e o mundo e também entre o ideal da vida e a visão de mundo). No entanto, deve-se aqui lembrar, uma vez mais, que a vivência não é constituída apenas pela estrutura da vida psíquica e que existem outras além dela, que, apesar de serem coinfluenciadas, são dela dependentes e, ainda assim, não podem ser tidas como fatos isolados (nem a estrutura da vida psíquica, nem quaisquer outras).

\section{A trans-historicidade do psiquismo e a hermenêutica das ciências compreensivas}

Como levar epistemologicamente adiante o psiquismo enquanto a estrutura mais fundamental, tendo em vista o fato de Dilthey buscar uma entidade que não seja trans-histórica, para combater o idealismo dos empiristas ingleses, assim como o idealismo transcendental kantiano? Colocar esta pergunta, no presente momento, ocorre diante da ocasião para a solução deste problema que nos ajudará a entender como o psiquismo se integra ao conjunto do pensamento diltheyano.

Deparamo-nos com esta falha, pois, a estrutura psíquica não preencheria a tarefa de ser não trans-histórica, sendo ela algo comum a todas as culturas de todas as épocas. Deste modo, mesmo Dilthey não teria conseguido mudar muita coisa desde Kant, apenas movendo um problema de um lugar a outro, transferindo as formas apriorísticas kantianas para a sua estrutura psíquica, tendo apenas aqui a diferença do condicionamento histórico como pano de fundo. (Cf. REIS, 2003). Tal pano de fundo histórico é aquele que permitiria à vida psíquica desenvolver-se, através das valorações, volições, sentimentos etc., que são dados única e exclusivamente pela época vivida. José Carlos Reis (2003) torna isso compreensível recorrendo à imagem das teclas de um piano. Afinal, 
ali, por mais que tenhamos todas as notas já definidas em cada tecla, poderíamos fazer infinitas combinações de sons para criar música, mas, ainda assim, apenas uma música poderia ser tocada por vez. Isto é: por mais que ainda houvesse algo anterior à possibilidade de condicionamento histórico, esse algo ainda seria mais adequado que o homem ideal e o a priori kantiano, justamente por poder ser moldado pela história. Em lugar do apriorismo de Kant, Dilthey propôs um anti-a priori.

Ressaltemos que Dilthey tem como ponto central de sua filosofia a fundamentação das ciências humanas, o que pode ser visto não apenas no subtítulo da Introdução às ciências humanas, sua obra principal: Tentativa de uma fundamentação para o estudo da sociedade e da história. Esse projeto deverá ser mantido ao longo de toda sua carreira.

Nessa refundamentação, o filósofo buscará a base mais fundamental do objeto de estudos das ciências histórico-sociais: a vida (tentando salvá-las do positivismo, muito em moda em sua época). Sua tarefa consiste em demonstrar como os positivistas, ao explicarem o objeto das ciências humanas pela lente das ciências naturais, apenas afastam-se dele. O cientista natural estudaria realidades abstraídas de qualquer relação com a experiência da vivência, cerne das ciências humanas. (DILTHEY, 2010b).

Nessa sua tentativa de compreensão das vivências, Dilthey oscilaria entre a análise da vida psíquica e as condições históricas que as influenciam, ora dando mais atenção ao indivíduo, ora orientando-se pela sociedade, porque indivíduo e sociedade seriam coinfluentes. Tanto quanto as valorações e volições são dadas pelo espírito de uma época, o indivíduo esforçar-se-á, graças ao seu ideal de vida para movê-lo. Em outras palavras, o indivíduo é responsável pelas mudanças de sua época (através da força de sua vontade gerada pelo seu ideal de vida em confronto com sua visão de mundo). E é ainda no projeto de fundamentação das ciências humanas que Dilthey vai utilizar-se do método hermenêutico para interpretar um texto, fosse dando ênfase ao seu autor ou à sua ambiência. (RODI, 1983)

Alguns autores consideram a hermenêutica diltheyana como sendo a primeira hermenêutica a esboçar traços propriamente filosóficos (RODI, 1985), tendo sido inspirada na hermenêutica filológica de Schleiermacher. A hermenêutica deste filólogo, por sua vez, foi a primeira a deixar de ser uma mera técnica interpretativa que perpassara a Idade Média e parte significativa da Modernidade. (CASANOVA, 2008) Segundo Hans-Ulrich Lessing (2011), Dilthey nunca se declarou hermeneuta, tampouco "schleiermacheriano" (tendo, inclusive, 
demonstrado posição um tanto quanto crítica contra ele), de sorte que constatamos, em sua filosofia, elementos muito distintos de tal tipo de pensamento.

Em verdade, Dilthey usa pouco e cuidadosamente o termo "hermenêutica". Esse uso reservado e discreto se deve ao fato de ele não encontrar-se em campo algum fora da teologia, jurisprudência ou filologia, a não ser de um modo um tanto quanto não usual. Esse termo, na inovação diltheyana, teria adquirido um novo valor de dois modos diferentes: o primeiro, na ampliação da abrangência de seu uso nas ciências humanas; depois, "pelo uso adjetivado 'hermenêutico' poder significar a mais alta exigência filosófica, mas também uma ofensa ao desmascaramento do exagerado desnorteamento metafísico" (RODI, 1985, p.150) (tal como nós vimos anteriormente, quando tratávamos dos empiristas ingleses, por exemplo, que, depositando todo seu pensamento na metafísica, afastavam-no de qualquer pretensão de lida com a realidade das vivências humanas). A classificação de hermeneuta será a Dilthey dada postumamente por outros filósofos (precisamente, Heidegger e Gadamer - cujas obras não poderiam ter sido sequer imaginadas sem a motivação diltheyana - e, mesmo assim, apenas por conta de sua obra tardia). (LESSING, 2011).

Com esse modelo de hermenêutica, Dilthey desenvolverá suas ideias a luz de uma hermenêutica das expressões das vivências, mas apenas no que se limita à compreensão de trabalhos escritos, tendo em vista o fato de ele diferenciar dois tipos de compreensão diferentes. (LESSING, 2011). Primeiramente, a compreensão "elementar" ou psicológica e trabalharia com o esquema de analogia com as vivências do outro; depois, haveria uma compreensão "mais elevada" ou hermenêutica que, de um modo diferente ou, talvez, mais elaborado, tem sentido e significação como meta e distancia-se da interpretação psicológica, pois se realiza através de obras escritas, compreendendo-as como produtos espirituais de substâncias autônomas viventes. Esta segunda interpretação desempenhará um papel mais central no contexto de uma hermenêutica como método de interpretação de textos, pois as vivências, não podendo ser compreendidas como um todo, mas apenas como parte de uma totalidade, a saber, a vida (justamente pelo fato de nem a vida nem a vivência poderem ser apreendidos num plano objetivo da realidade) se fará necessário todo um processo para o esforço no sentido da interpretação que passe pelos âmbitos subjetivos espirituais da vivência, para que se alcance sua compreensão. (MAKKREEL, 1984).

A presente interpretação das vivências humanas, partindo da compreensão da própria vida, terá seu início com um princípio-chave para a hermenêutica não só de Schleiermacher, que o formulou de modo mais explícito, mas que 
tem suas origens na retórica da Antiguidade, o chamado "círculo hermenêutico". "Trata-se da relação circular entre o todo e suas partes: o significado antecipado em um todo se compreende por suas partes, mas é à luz do todo que as partes adquirem a sua função esclarecedora." (GADAMER, 1998, p. 58). Schleiermacher não chegou a formular esse princípio com base em vivências, mas foi Dilthey que dele se apropriou para a interpretação delas.

O que o círculo hermenêutico representa é o fato de nunca partirmos de um ponto totalmente vazio de conhecimento para uma interpretação, mas termos sempre já certos sentidos prévios à nossa disposição. Visto desta maneira, este círculo hermenêutico está, realmente, muito mais próximo de uma oscilação do que de um círculo vicioso lógico, como era comparado há dois séculos. Poderíamos usar de uma oscilação para ilustrá-lo com muito mais precisão, não somente para afastá-lo de qualquer pretensão de comparação com um sistema lógico-matemático (RODI, 1985), mas também porque Dilthey não se prende somente a um tipo de escopo de seu estudo. Afinal, o filósofo analisa o indivíduo através da psicologia para, logo depois, descrever sua época com a história, assim como a sua estrutura psíquica e, em seguida, analisar as condições sócio-culturais que as influenciaram e assim por diante. (Cf. DILTHEY, 1992).

\section{Conclusões}

Ao fim deste breve exercício de delimitação, que se debruçou especialmente na obra Teoria das concepções de mundo, podemos concluir que, para Dilthey, o psiquismo é estrutura fundamental às vivências, apesar de em sua formulação ainda possui, residualmente, vestígios de uma figura trans-histórica. Com base na bibliografia de apoio (especialmente Lessing e Rodi), validamos a hipótese inicialmente apresentada ao depreender que se, inicialmente, isto poderia nos parecer um tanto quanto incoerente, visto que o filósofo buscava resolver questões originadas da tradição metafísica, esta que postulava verdades universais, quando elas seriam, na verdade, produtos da visão de mundo de suas respectivas épocas. Essas expectativas, entretanto, não se concretizaram no pensamento do autor, pois ele, no contexto da fundamentação das ciências humanas, pelas vias do método hermenêutico, pôde conciliar psicologia e história. Essa conciliação se sustenta no fato da estrutura psíquica por ele proposta, apesar de ainda ser trans-histórica, levar em conta o condicionamento histórico para seu desenvolvimento por meio das vivências. 
CASANOVA, Marco Antônio S. A vida da linguagem compreensiva. In: Mente e cérebro - Filosofia 11: Presença do outro e interpretação, São Paulo, p. 66-73, 01 ago. 2008.

DILTHEY, Wilhelm. A construção do mundo histórico nas ciências humanas. Trad. Marco Antônio Casanova. São Paulo: UNESP, 2010.

$$
\text { - Ideias sobre uma psicologia }
$$
descritiva e analítica. Trad. Marco Antônio Casanova. Rio de Janeiro: Via Verita, 2011. Introdução às Ciências Humanas

- Tentativa de uma fundamentação para o estudo da sociedade e da história. Tradução: Marco Antônio Casanova, Forense Universitária, 2010. . Teoria das Concepções de Mundo - A consciência histórica e as concepções do mundo - Tipos de concepção do mundo e a sua formação metafísica. Trad. Artur Mourão. Lisboa: 70, 1992.

GADAMER, Hans-Georg. O problema da consciência histórica. Org.: Pierre Fruchon. Trad. Paulo César Duque Estrada, Rio de Janeiro: Fundação Getulio Vargas, 1998.

JUNG, Matthias. Dilthey zur Einführung. Hamburg: Junius, 1996.

LESSING, Hans-Ulrich. Wilhelm Dilthey. Köl, Weimar, Wien: Böhlau Verlag GmbH \& Cie, 2011.

MAKKREEL, Rudolf. Dilthey and Phenomenology. In Dilthey Jahrbuch für Philosophie und Geschichte der Geistewissenschaften. Göttingen: Vandenhoeck \& Ruprecht, v. II (1984), p. 346-350.
. Dilthey und die interpretierenden Wissenchaften Die Rolle von Erklären und Verstehen. In Dilthey Jahrbuch für Philosophie und Geschichte der Geistewissenschaften. Göttingen: Vandenhoeck \& Ruprecht, v. I, (1983), p. 57-73.

REIS, José Carlos. Wilhelm Dilthey e a autonomia das ciências histórico-sociais. Londrina: Eduel, 2003.

RODI, Fritjof. Diltheys Kritik der historischen Vernunft - Programm oder System? In: Dilthey - Jahrbuch für Philosophie und Geschichte der Geisteswissenschaften. Göttingen: Vandenhoeck \& Ruprecht, v. III (1985.), p. 140-165.

. Über einige Grundbegriffe einer Philosophie der Geistewissenschaften. In Dilthey - Jahrbuch für Philosophie und Geschichte der Geistewissenschaften. Göttingen: Vandenhoeck \& Ruprecht, v. I (1983.), p. 260-267.

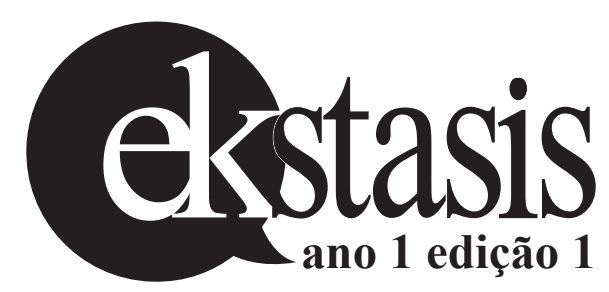

